\title{
Diacronía sobre el \\ fenómeno Big-Band en Colombia
}

\section{Articulo de investigación}

Henry José Cáceres Cortés

Universidad de Pamplona, Colombia

hjcaceres@unipamplona.edu.co

\section{Henry Julián Cáceres Ramón}

Universidad Nacional de Colombia

hcaceresr@unal.edu.co

Recibido: 22 de octubre de 2018

Aprobado: 18 de marzo de 2019

Cómo citar este artículo: Cáceres Cortes, Henry José; Cáceres Ramón, Henry Julián. (2019). Diacronía sobre el fenómeno Big-Band en Colombia (Articulo de Investigación). Calle 14: revista de investigación en el campo del arte 14(26). pp. 348-363. DOI: https://doi. org/10.14483/21450706.15008

\section{(). (1)}

https://creativecommons.org/licenses/by/4.0/deed.es 

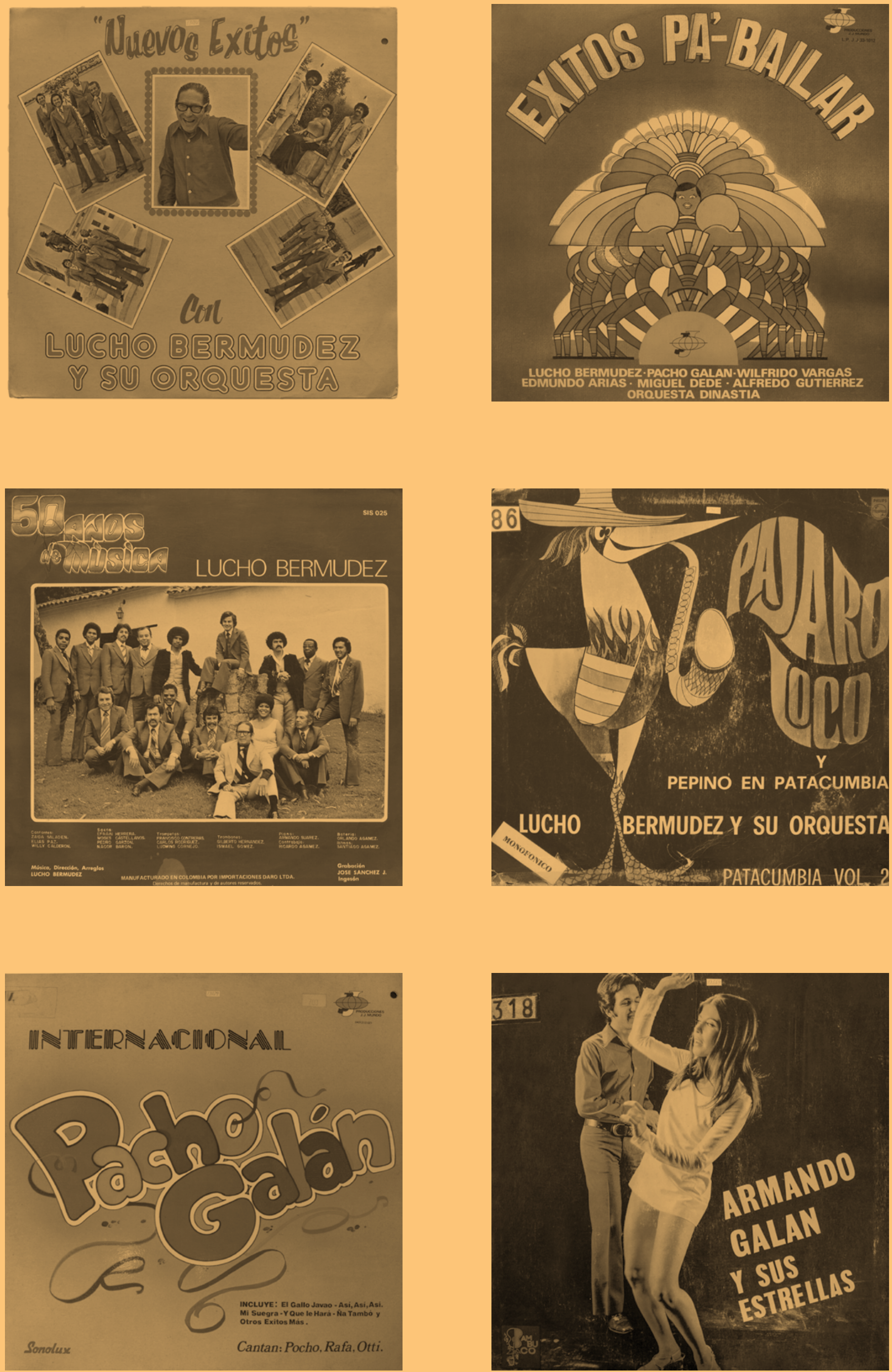


\title{
Resumen
}

En el interior de la historia musical de Colombia hicieron presencia las orquestas Big-Band; por intermedio de ellas se instauraron procesos de desarrollo artístico musical, debido a estos acontecimientos nacieron diversos movimientos musicales condensados en forma de expresiones de todo tipo, que causaron hasta la actualidad transformaciones culturales sobre todo en el ámbito musical, fueron considerables los músicos que a través de su magia, de su tenacidad y pasión dejaron magnífica herencia a las generaciones presentes y venideras, contribuyendo de esta manera a la reproducción de la música elaborada por las distintas agrupaciones musicales, que aparecen en la escena de las diferentes regiones del país en un estricto orden cronológico, cabe mencionar además que sucesos tales como el progreso en las vías terrestres y el perfeccionamiento de la radio desempeñaron incuestionables papeles integradores para crear nuevos prototipos musicales productos de la fusión con las músicas folclóricas fundidas con las orquestas de gran formato, hasta estructurar el patrimonio musical nacional en rincones y diversas regiones del país.

\section{Palabras clave}

Big-Band; diacronía; música; cultura; sociedad; Colombia

\begin{abstract}
When big bands appeared in the musical history of Colombia, several processes of musical and artistic development were established, that in turn produced musical movements that condensed expressions of all kinds, causing cultural transformations, especially in the musical field. These musicians left through their magic, tenacity and passion a magnificent heritage to the present and future generations, contributing in this way to the dissemination of the works of many musical groups from every region in the country, which here appear in strict chronological order. It is also worth mentioning that events such as the growth of land routes and the improvement of the radio played an unquestionable integrating role to create new musical prototypes, products of the fusion of folk music with the format of large orchestras. This furthered the national musical heritage throughout the country.
\end{abstract}

\section{Keywords}

Big band; diachrony; music; culture; society; Colombia

\section{Résumé}

Lors de l'apparition des big bands dans l'histoire de la musique en Colombie, plusieurs processus de développement musical et artistique ont été mis en place, qui ont à leur tour donné lieu à des mouvements musicaux condensant des expressions de toutes sortes, entraînant des transformations culturelles, en particulier dans le domaine musical. Par leur magie, leur ténacité et leur passion, ces musiciens ont légué aux générations présentes et futures un patrimoine magnifique, contribuant ainsi à la diffusion des œuvres de nombreux groupes musicaux de toutes les régions du pays, qui apparaissent ici dans un ordre chronologique strict. Il convient également de mentionner que des événements tels que le développement des routes terrestres et l'amélioration de la radio ont joué un rôle intégrateur incontestable dans la création de nouveaux prototypes musicaux, produits de la fusion de la musique folklorique avec le format de grands orchestres. Cela a favorisé le patrimoine musical national dans les différentes régions du pays. 


\section{Mots clés}

Big band; diachronie ; musique ; culture ; société ; Colombie

Diacronia em torno do fenômeno Big Band na Colômbia

\section{Resumo}

Quando as big bands apareceram na história musical da Colômbia, foram estabelecidos vários processos de desenvolvimento musical e artístico, que por sua vez produziram movimentos musicais que condensavam expressões de todo tipo, provocando transformações culturais, especialmente no campo musical. Estes músicos deixaram através da sua magia, tenacidade e paixão um magnífico patrimônio para as gerações presentes e futuras, contribuindo assim para a divulgação das obras de muitos grupos musicais de todas as regiões do país, que aqui aparecem em estrita ordem cronológica. Também vale a pena mencionar que eventos como o crescimento das rotas terrestres e a melhoria do rádio desempenharam um inquestionável papel integrador na criação de novos protótipos musicais, produtos da fusão da música folclórica com o formato de grandes orquestras. Isso promoveu a herança musical nacional em todo o país.

\section{Palavras-chave}

Big band; diacronia; música; cultura; sociedade; Colômbia

\section{Diacronía fenomenomanda Big- Band Colombiape}

\section{Maillallachiska}

Ukuma antiva tuanipe Colombiape kauachirkakuna tunadurkuna Big- Band, paikunamanda nispa churarkakuna artístico tunai, kaimanda nispa llugsirkakuna achka tunadurkuna sug rigcha, sug rigcha, kauachinaku iapa suma tunai kunaura, karkakunami Achka tunarkuna iachakuna sakirkakuna suma iachaikuna tunangapa, kunauramanda rurakunata i samuna kugtapa aidachispa chasa uiñachingapa tunaikuna grupo tunadurkunata llugsiskakunata sugpe sugpe Tukui Colombiape rimarime chimandak imasame rurarkakuna ñambikuna suma uiangapa uiadiru karkakuna aidadurkuna uiñachingapa musu tunaikuna runakuna iachaskasina ruraska atun tunadurkunamanda i sakingapa antiuasina tunaikuna tukuikunamanda daca kuchupi Tukui paispe.

\section{Rimangapa Ministidukuna}

Big- Band; diacronía; tuanai; sugrigsiska; tukuikunaua Colombia 


\section{Introducción}

El presente escrito tiene la intención de establecer reflexiones sobre los acontecimientos significativos, que ocurrieron alrededor del fenómeno musical BigBand en Colombia y toda su evolución, enmarcado desde luego dentro de una línea del tiempo; para mayor garantía en la manipulación de la información se estableció el proceso de investigación y revisión de literatura acerca de la temática en particular, ¿Cómo no pensar en la evolución de las Big-Band en Colombia?, dentro de la historia, las orquestas tipo Big-Band, marcaron gran referencia, a causa de las diferentes formas de poner en escena la música, su repertorio y sus representaciones fundadas en la improvisación, cualidad característica de la música africana y del jazz, sucesos sobrevenidos en Norteamérica que se diseminaron en toda la aldea global y Colombia no fue un territorio que estuvo exento de las embestidas de estas nuevas formas de expresión musical, en ese mismo orden de ideas cabe aclarar que en el contexto Colombiano estas tradiciones artísticas inmortalizaron sus prácticas musicales con grandes composiciones a través de la historia y estas costumbres se han mantenido en Colombia, sufriendo de alguna manera transformaciones propiciadas en el ámbito cultural.

Es imprescindible mencionar además, que se constituyó una estructuración, organizada, para el análisis dentro del orden de la historia, para que se comprenda de una manera más efectiva, el complejo fenómeno de la tradición musical, realizando el esfuerzo por captar los patrones de organización, vistos como un todo o como un sistema, que se descompone, y de esta manera, visualizar elementos simples, tomando como referente diferentes agrupaciones que se destacaron en la historia musical del movimiento Big-Band de nuestro país. Todo el esfuerzo anterior con el firme propósito de propiciar reflexiones, elaboraciones, aportes académicos e innovadores a las comunidades científicas musicológicas contemporáneas.

\section{Retrospectiva: los inicios de orquestas Big-Band en Colombia}

Ahora bien desde el mismo momento en que desembarcaron los tambores africanos en el conteniente Americano, se juntaron con las músicas del contexto nativo raizal, produciendo una minuciosa mutación consistente en formas musicales novedosas de expresión; a la par con la estructuración y evolución social, se diseminaron estas nuevas formas por todas las latitudes, propiciando cambios en las agrupaciones musicales desde las décadas de los años treinta en adelante, dicho de otro modo, se gestaron desde esa época, nuevas formas de componer, de orquestar, de organizar y gestionar la música, una de ellas y que progresó fue la de las Big-Band, las cuales se establecieron en representaciones de nuevas armonías, rítmicas y evocaciones patrimoniales, debido a la misma necesidad de preservar la cultura ancestral, a través de la música como lenguaje de comunicación, legado que poco a poco se fue extendiendo por los caminos de toda América Latina, de otro modo habría que decir también, que Colombia no fue ajeno a estos procesos de interinfluencia, hibridación o mezcla musical de donde resultaron diversos movimientos musicales, algunos de ellos organizados en forma de Big-Band, y otras representaciones como bandas musicales de viento y música de cuerda.

Vale la pena mencionar que los tambores africanos no solo aportaron a la estructuración del swing, y del mismo jazz en el continente, su gran influencia se extiende por toda América, por ejemplo, el resultado del hibrido entre las músicas españolas y las africanas surge alrededor de los años 1840-1950, en forma de: rumba, son cubano, mambo, songo, danzón, guaracha, chachachá, son montuno, ubicados en el afro-caribe americano y que posteriormente evolucionaron en ritmos nuevos como la salsa y el merengue (Mauleón, 1999, p. 9).

Toda esta amalgama de expresiones musicales se expanden gracias al fragor de los avances de la industria del cine y televisión y la consolidación de los medios de transporte, en donde la aviación toma fuerza y la captura de la música en unos discos redondos llamados acetatos, y su posterior difusión en Colombia en los medios masivos de comunicación: en este sentido la Radiodifusora Nacional sirvió como gestor del momento. Todo lo anterior, hace deliberar que, en el interior de los procesos de expresión musical, las Big-Band, también fueron protagonistas y dejaron grandes marcas iconográficas, en los diferentes espacios sociales con características propias de ser valoradas y descritas de forma considerable.

De otro modo es sabido que los avances sociales se consiguieron por la capacidad de los sujetos, de innovar y su tenacidad por prosperar, habría que mencionar también la habilidad que propiciaron las culturas desde la edad precolombina, para utilizar los ríos como medios de transporte, fueron estas actividades, las que dieron como resultado que los asentamientos trascendieran de alguna forma, hasta la actualidad, a través de las construcciones de caminos de herradura, caminos reales y 


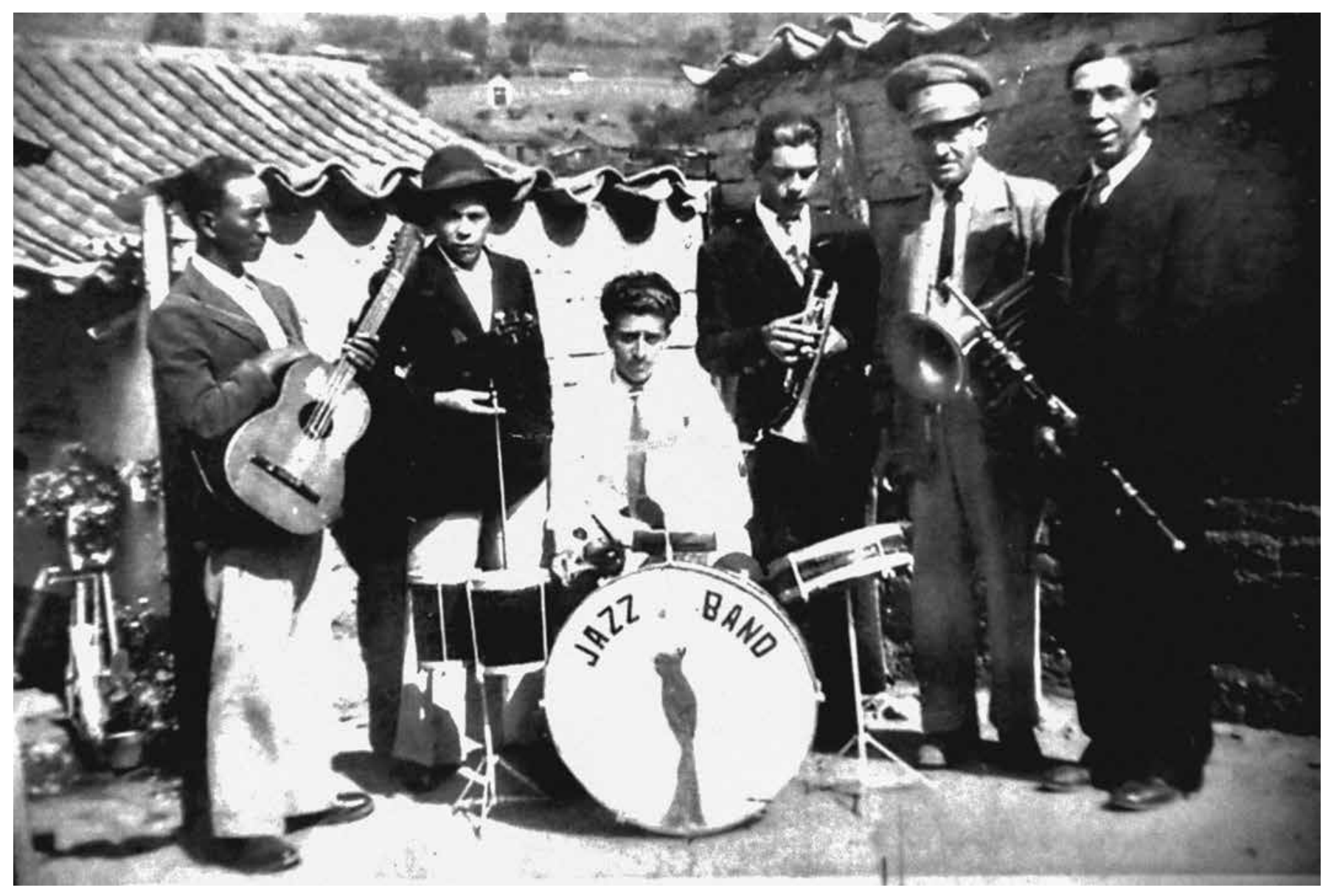

Imagen 1. Músicos de provincia integrantes de una Jazz Band (Norte de Santander, 1930). Archivo Museo de Toto Villamizar.

con posterioridad las vías férreas en las sabanas, llanuras, valles y cordilleras de Colombia, más no se trata tan solo de referenciar como fue la historia de los caminos de Colombia, la intención inicial parte de destacar el papel que desempeñaron las vías, como puentes de dispersión de la música en forma de tradición oral y escrita, relacionados con el despliegue de formatos musicales tipo Big-Band, en asocio con el progreso de las vías férreas en Colombia (Osorio, 2014, p. 3)

Si se realiza una conexión racional con la anterior referencia se establece que la evolución y modernización de las vías, en este sentido férreas, no solo facilitaron en Colombia la dinámica comercial, alrededor de ellas nació también, el intercambio cultural. Y, por supuesto, la música de las grandes orquestas, se hizo presente con gran prominencia alrededor de todo este complejo social.

Otro rasgo importante fue: la intermediación de medio de transporte del río grande de la Magdalena, que intervino de forma significativa en la propagación, no solo de las músicas provenientes de la parte norte del conteniente, simultáneamente difundió las músicas de la zona atlántica hacia el interior del país, produciendo suculentas mezcolanzas de música costeña, con las provenientes del altiplano cundi-boyacense y hasta procedentes del sur del país, este argumento corresponde muy bien ya que sobre las embarcaciones que navegaban en el río Magdalena, viajaban grupos de personas que hacían su música, para que el viaje de los pasajeros fuera menos quejumbroso, esta parece ser era una práctica que se realizaba recurrentemente mucho antes de se diera paso a la construcción de las carreteras, las vías terrestres y las férreas.

Todas las anteriores observaciones parecen relacionar y justificar el hecho de que el surgimiento de las grandes agrupaciones musicales en Colombia se localizó inicialmente, por la zona de la costa atlántica, posiblemente por la bondad de la posición geográfica, al mismo tiempo por la facilidad del transporte sobre el rio magdalena y sus tributarios. 


\section{Inicios año 1917}

La ciudad de Cartagena fue privilegiada por ser la localidad que concibió la Jazz Band Lorduy (Oliver, 2009, p. 47) alrededor de 1917; la condición de ser uno de los principales puertos de Colombia, la facultó para que sucedieran en su entorno, no solo acontecimientos ligados a su historia pirata y de murallas, también acaecieron brotes culturales, debido a la idiosincrasia de su gente, en este caso las primeras Big-Band comienzan a florecer en este ambiente caribeño.

Hay otro aspecto entre tantos, el reconocimiento dentro de la historia del músico: Adolfo Mejía, nombre que aparece en la escena, debido a sus grandes aportes innovadores en la transformación musical, producto de su formación; en ese orden de ideas Muñoz (2007, pp. 63-64) afirma que Mejía, fue el primer músico colombiano que viajó a Estados Unidos; después de estudiar, capacitarse y tener su experiencia en el norte del continente, trae sus saberes y combina lo aprendido en los escenarios del jazz con los ritmos y expresiones vernáculas, este músico en 1929 adoptó los ritmos de la costa caribe y del interior del país en los ensambles de la Band Lorduy, se podría afirmar que el gran: Adolfo Mejía fue para las agrupaciones Big-Band lo que José Rozo Contreras, a las bandas musicales de viento, ambos trajeron sus saberes a Colombia como resultado de sus capacitaciones, el primero en Estados Unidos y el segundo en Europa.

Por otro lado, habría que decir también que Adolfo Mejía, fue el músico pionero, quien rompió el sello de los estereotipos musicales formales en Colombia, se le agradece el esfuerzo por lograr conformar orquestas de gran formato, antes que surgiera el nombre del maestro Sosa alrededor en 1934 con su orquesta Jazz Band Sosa.

Conviene sin embargo, advertir sobre las relaciones de índole organizacional-musical, que se presentaban en la época, debido a las mismas interacciones entre distintos sectores sociales: la preponderancia de la disposición de los músicos para viajar al exterior y recibir formación académica, de otra parte, la demanda tanto de los grandes clubes, bailaderos y hoteles como las peticiones de músicos de parte de emisoras para ambientar los programas que se hacían con música de orquestas tocada en vivo (Oliver, 2009, p. 73).

\section{Las Big-Band de los años 30}

Gradualmente se observa cómo se va engranando la historia musical alrededor de las orquestas Big-Band en Colombia.

Sosa comenzó en 1927 con la "Jazz Band Barranquilla" y la "Orquesta Sosa" fue conformada a principios de los años 30 hasta 1939. Murió en 1938 cuando su yerno, Pedro Biava, ya había asumido la dirección de la orquesta; nacido en Roma en 1903. (Wade, 2002, p. 108)

Por simplicidad se puede suponer, que los intereses iniciales de hacer jazz, fueron la excusa perfecta y el objeto integrador, para que desde allí se diseminaran distintas vertientes, sobre todo de repertorio de música folclórica, propia de la identidad sonora de las distintas regiones del país, entonces conviene referir lo ocurrido alrededor de la orquesta Jazz Band de Sosa, conformada en 1930 hasta su disolución en 1939. Tras la muerte de su director y fundador Sosa, Pedro Biava toma las riendas, haciendo que esta agrupación se niegue a su pronta decadencia.

Por otra parte, lo hecho por varios representantes dejó improntas indisolubles producto de las vertiginosas formas de representación musical, que se propiciaron en el momento, hecho que llevó a que despertaran en otros músicos de diferentes regiones, inquietudes e intereses por la música de Big-Band, y de esta manera seguir por la misma ruta sonora; por eso cabalmente como resultado de estos movimientos musicales una vez extinguida la orquesta del maestro boyacense: Luís Felipe Sosa, aparece en el escenario la Atlántico Jazz Band, fundada por el trombonista Guido Perla.

Luego de la muerte de Sosa, el trombonista Guido Perla formó la "Emisora Atlántico Jazz Band", una agrupación que durante una década dominó la escena musical barranquillera y que recogió a muchos de los integrantes de la "Orquesta Sosa", Peñalosa entre ellos. (Wade, 2002, p. 109)

Se tiene como consecuencia que esta agrupación, sin duda gozó de gran reconocimiento, no solo amenizaba en las localidades de la costa norte colombiana, de manera simultánea, hacía presencia en la radio Atlántico de Barranquilla, como orquesta de planta, en este orden de ideas: la Atlántico fue una de las agrupaciones pioneras en la proyección y reproducción musical para el momento de los hechos. (Candela, 1986, 
p. 14) citado en (Oliver, 2009, p. 48) expone claramente que: la Atlántico Jazz, prácticamente se convierte en un nicho de emprendimiento musical, porque allí se aglomeraron no solo los músicos más distinguidos de la región, sino los más virtuosos musicalmente hablando, por su capacidad y facilidad de arreglar y adaptar, repertorios basados en el jazz, de música cubana, incluyendo trascripciones de compositores de la talla de Glenn Miller entre muchos otros.

Tras estas digresiones y avanzando progresivamente, alrededor de 1939 afirma Samper, (2003, p. 1) aparece en el escenario el nombre de Gilberto, hijo del músico Lascarro, que vivió en Nueva Orleans e integró la Dixieland Band Jazz y simultáneamente se desempeñó como músico de la orquesta de Luis Felipe Sosa, y de la Big-Band Barranquillera llamada blanco y negro, agrupación que compartió mano a manos, como se llamaban en aquel tiempo con la orquesta Casino de la Playa de La Habana, esta última, orquesta que utilizó los recursos sonoros de las grandes Big-Band NorteAmericanas, para dispersar no solo el jazz sino la música folclórica cubana en todo el territorio.

El siguiente aspecto, trata de describir la importancia y las peculiares caracterizadas de alegría, expresividad y creatividad de los músicos de las poblaciones provenientes de la Costa Atlántica, no solo de Barranquilla, de la actitud emprendedora de los paisas, la capacidad de los músicos capitalinos, el sabor de los cueros de los caleños; se debe agregar también que ellos concibieron, sin lugar a dudas movimientos musicales transcendentales con nuevas posibilidades, de esta manera, emergieron en distintas ciudades de Colombia agrupaciones tipo Big-Band, acontecimiento que presagiaba la evolución y consolidación, no solo del gran formato de orquesta, sino de un movimiento que se gestaba, gracias a que el país se encontraba en pleno desarrollo comercial y cultural, no se debe olvidar que a mediados de 1937, la discográfica RCA Víctor, ya se encontraba instalada en la ciudad de Medellín, ante este hecho del inicio de la grabación de la música, se produce como consecuencia una sana competencia de los músicos, por participar en las grabaciones de las producciones musicales, de las disqueras que las efectuaban en ese momento.

\section{Expansión hacia otros territorios de Colombia: (la transición de las orquestas del jazz a la música popular y folclórica)}

Añádase al nacimiento de las grandes orquestas en Barranquilla y Cartagena, los inicios de la conformación de orquestas en otras regiones diferentes a la Costa Atlántica, con características y arquetipos similares, pero diferenciadas ya por su repertorio, por consiguiente, se comienza a dejar el jazz de lado, y se incorporan en el repertorio músicas eruditas latinoamericanas mezcladas con fundamentos de las músicas raizales y tradicionales costeñas.

Por otro lado, es preciso aclarar que, además de lo sucedido en la Costa Atlántica, se surgieron brotes de jazz bands en otros lugares como Ciénaga, Zambrano, Mompox, Sincelejo, Corozal, Valledupar, la región del Sinú, Medellín, Cali y Bogotá, que se convertirían en zonas de contacto geográfico. (Oliver, 2009, pp. 46-47)

Pero antes de seguir, lo que interesa ahora es observar, la inclusión dentro de los repertorios, músicas indígenas, músicas de montaña como se la llamaba a la músicas del interior del país, referentes a pasillos a 3/4, bambucos a $3 / 4$ con intensión de $6 / 8$, algunas polkas, pasodobles y danzas; orquestadas para el gran formato y la generación de nuevos estilos y ritmos, aumentando de alguna forma el mapa musical de Colombia, hay que reconocer que estas manifestaciones colmaban, las necesidades de la sociedad, en donde empiezan a aparecer en los carteles nombres como Luis Eduardo Bermúdez Acosta, Lucho Bermúdez y Francisco Galán Blanco; cabe señalar la responsabilidad social y comercial en ese entonces, de la radio, en el compromiso de mantener de forma inconsciente a las primeras orquestas Big- Band en el Caribe y otras regiones de Colombia.

\section{Los extraordinarios años cuarenta}

Llegando hasta este punto, posterior a que Pacho Galán realizara su paso por la orquesta del maestro Sosa, comenzó a realizar labores de director y arreglista de dicha orquesta, esto, gracias a toda la actividad que hizo en la Atlántico Jazz Band y a su notable capacidad y desempeño musical (Wade, 2002, p. 110).

Cuando se muere Sosa y se crea la Atlántico Jazz Band en 1940, pasa a ser el arreglista de 
la mayoría de los porros, guarachas, cumbias y fandangos que interpretara o grabara la Atlántico Jazz Band. (Wade. 2002, p. 110)

En pocas palabras "Pacho" ilustra su habilidad en la Emisora Atlántico Jazz Band, en una combinación de colores musicales, que retrató no solo en el jazz, sino en la música erudita. Galán, deja las orquestas de Sosa y Atlántico Jazz Band, y conforma la propia, alrededor de 1942, para dedicarse a algo más popular, rompiendo la forma tradicional y habitual de ensamblar la música en los repertorios de las grandes orquestas, incorporando compilaciones nacidas del sentir del pueblo. Pacho deja el jazz de las antiguas orquestas reservado para un público selecto, y da paso a: "cosita linda, la butifarra, rio y mar, boquita salá, los fandangos, cumbias, porros y su merecumbé"; manifestaciones más populares, que cautivaron a todos los colombianos, y que escuchan hasta nuestros días formando la propia identidad musical nacional, para convertirse en uno de los precursores encargados de dejar improntas, no solo en la memoria colectiva musical de Colombia, sino estableciendo la herencia de las grandiosas orquestas de música tropical; de esta forma enlazó la costa norte con el interior del país, a través de su música que extraía y componía, fruto de la musa creativa, de la observación de la naturaleza y del paisaje geográfico. Si se reflexiona las labores musicales que hacían recurrentemente estos músicos, eran las primeras escaramuzas de manifestaciones de fusiones musicales, que comienzan a gestarse de forma inconsciente en la Colombia contemporánea, puesto que la intención primera no fue la de sentarse a escribir obras, con formas musicales provenientes de distintas músicas y de diversas regiones del país, el propósito era plasmar el sentir cotidiano de un pueblo, igualmente, comunicar un lenguaje cargado con nuevos ritmos sincopados y armonías que contagiaban, a causa del sabor costeño.

Y cuando Pacho asumió el porro, lo hizo a la manera que lo había aprendido en la Orquesta Sosa y Emisora Atlántico Jazz Band. No es casual que sea, sin pretenderlo, porque siempre estuvo buscando otras cosas, uno de los pilares del porro atlanticense por la vía de 'Librada', 'El brazalete', 'Boquita salá' y otras, convertidas por Billo's Caracas Boys en 'La Butifarra', 'La casa de Fernando' y otras. (Samper, 2003, p. 6)

Es prudente advertir que se trataba simplemente de orquestar y arreglar la música popular y folclórica, que solo era escuchada en ese entonces por parte de la sociedad, tanto del litoral como del interior del país, ya que las elites tanto costeñas como del interior, escuchaban música Europea, por cuanto las músicas costeñas eran miradas de soslayo, dado que eran inapropiadas para el exquisito oído de la clase alta, y se las consideraba con condición peyorativa como del vulgo, alborotadora y bulliciosa.

\section{El comienzo: la revolución musical}

Estos músicos insinuaron grandes cambios en las distintas regiones del país, con la actitud de proyectar los diferentes estilos, en un nuevo imaginario musical hasta llegar casi a producir otra subcultura musical, junto con las músicas del interior, ya que la música costeña hecha por las Big-Band del momento, era una rica combinación de ritmos autóctonos con los africanos, con las músicas indígenas y con los ritmos españoles, consecuencia de la hibridación cultural del indio, negro y del blanco; de la asociación de lo nativo, con las manifestaciones españolas, de la alianza entre lo rural y la urbano; esta dinámica dio como resultado nuevas simbologías y fusiones complejas dentro de la organización cultural, con las cuales se identifica la sociedad, al respecto:

Bajo el aspecto de culturas populares. Es en estos escenarios donde estallan más ostensiblemente casi todas las categorías y las parejas de oposición convencionales (subalterno/hegemónico/, tradicional/moderno) empleadas para hablar de lo popular. Sus nuevas modalidades de organización de la cultura, de hibridación de las tradiciones de clases, etnias y naciones requieren otros instrumentos conceptuales. (García, 1999, p. 263)

Se puede establecer que la música hecha por las Big-Band es la praxis humana que se manifiesta como réplicas, dentro de un paisaje intangible en el interior de un contexto social, las nuevas resignificaciones culturales son el fruto de la cotidianidad de los pueblos, que se ocasiona dentro de las prácticas sociales; de acuerdo con ello, se pueden manifestar día con día, nuevas formas de transferencia, o por lo menos, emergentes caracterizaciones de la música tocada por las Big-Band, dentro de los espacios y entornos sociales, en otras palabras, el hacer de los músicos rompe esquemas y esta práctica nace con nuevos atributos, en función de la relación música y sociedad, las nuevas condiciones estructuradas por la relación: música y sociedad, estructuró a su vez nuevas costumbres, tanto del entorno sonoro como de la labor musical. Como se advierte en la 
anterior anotación la música como cultura, es entendida como la representación más sublime de la sociedad; de conocimiento, prácticas y creencias que se pronuncian dentro de la vida diaria y que se transmiten de generación en generación, pero que puede sufrir cambios por estar expuestas a la misma dinámica social y de la presencia e influencia de otras culturas. La cultura musical se tornó en un espacio de reconocimiento y de identidad de la sociedad colombiana.

\section{Análisis del papel de la radio en la conformación de orquestas Big-Band en Colombia}

Hay otro aspecto, entre tantos, que no se puede pasar desapercibido, es el papel que desempeñó la radio, para empoderar los movimientos musicales realizados por las grandes orquestas. Hay que reconocer que la misma dinámica característica de la radio como medio de difusión, para la época, exigía que las agrupaciones musicales se presentaran sin ningún tipo de equipos de sonido de apoyo, solo eran amplificadas por los medios con los cuales contaban las emisoras, consistentes muchas veces en dos o tres micrófonos; más aún las condiciones de los sistemas análogos de las emisoras y de los métodos de grabación, eran para la época tecnologías muy incipientes puesto que las transmisiones se realizaban en amplitud modulada, situación que demandaba a las agrupaciones musicales exigencias técnicas al interpretar, en ese mismo orden de ideas, toda la puesta en escena de los programas radiales, se hacían en vivo; no había espacio para los errores musicales, contrariamente y a pesar de las precarias condiciones técnicas con que se hacían las transmisiones, la radio desempeñó un papel integrador, de difusión porque este era el medio más acorde y expedito, a través del cual las estaciones hacían que un vasto auditorio escuchara diferentes músicas y cada individuo se fuera identificando socialmente, con las distintas músicas por medio de una realidad simbólica que trasmitían las ondas radiales.

\section{La apertura de las exuberantes mutaciones}

Prosiguiendo con el presente análisis del fenómeno BigBand en Colombia y en la línea del tiempo, vale la pena recordar que: Lucho Bermúdez y Pacho Galán después de su servicio como músicos en la Atlántico Jazz Band, fundaron sus propias orquestas.
Los gestores de la evolución de nuestra música popular, ambos con clara influencia del jazz en sus composiciones y en el formato de big band que sus orquestas seguían (Muñoz, 2007, p. 63).

A pesar de que la base del repertorio de la Atlántico Jazz Band se apoyó en el jazz, el blues, y el foxtrot, se incluyeron igualmente guarachas, porros, cumbias y gaitas; como resultado de esta práctica, adquirieron incuestionables experiencias extraordinarias y aprendizajes musicales, que les significaron adquirir competencias, habilidades y capacidades para lograr cautivar y consolidar las nuevas dimensiones de las futuras generaciones, ya que como precursores de las grandes orquestas en Colombia, dieron un enfoque distinto al jazz, creando nuevas formas y nuevos estilos con diferentes posibilidades de hacer música, pero utilizando recursos del jazz.

Por otro lado, en el año 1941 como es sabido, se consolida en la palestra musical de nuestro país, el genio, Luis Eduardo Bermúdez Acosta, que aportará con gran significancia al surgimiento de agrupaciones de grandes formatos; por consiguiente, es necesario hacer una mirada en retrospectiva al periodo de la posguerra; en la sociedad colombiana, para aquel entonces, en ciudades de la costa norte, que hasta ahora se estaban configurando en su desarrollo urbano e industrial por la década del cuarenta, se asume que lo llevado al plano de la composición musical radicaba en lo que sucedía cotidianamente en los entornos de los grandes músicos, en este caso los sucesos que rodearon a Lucho, y que luego los volvió melodía, tras haber adquirido su habilidad musical para la improvisación en las orquestas de Sosa y Emisora Atlántico Jazz Band, pasaría a aplicar los jam session, en los solos que ejecutaba tocando los porros, gaitas, mapalés, entre otros ritmos con su orquesta.

En 1941 Lucho Bermúdez arma su propia orquesta que es la llevada a Bogotá en el año 1944, su sensibilidad y su capacidad creativa lo lleva a impactar la sociedad no solo colombiana, sino que su música se expandió a otras partes del continente.

Con su capacidad artística fue generando y propiciando un lenguaje de encuentro de las regiones para hablar de nación en términos sonoros. Lucho Bermúdez vistió de frac el porro y la cumbia.(Señal Colombia, febrero, 2013)

Como se anotó con anterioridad, pueda ser que la primera orquesta que conformó Lucho, no tuviera las 
finalidades primordiales de hacer, blues, swing o jazz, a pesar de que se los incluía en el repertorio; pero se considera la importancia que tiene este hecho para la historia musical de Colombia, ya que su estructura organizativa y organológica, presentó las caracterizaciones semejantes a las que poseen las orquestas tipo BigBand Norteamericanas, pero con música colombiana compuesta por el mismo Lucho, en otras palabras, una agrupación musical conformada por un número significativo de músicos (entre veinte y veinticinco) con el solo propósito de expandir las músicas indígenas de gaita, por toda la aldea global.

Todas las faenas musicales que realizara Lucho Bermúdez con su orquesta de música tropical, sui generis, fueron incomparables tanto en el campo compositivo, como de las diferentes formas de orquestar, lo cual propició una inexorable conexidad, primero social ya que todos los hombres y mujeres de todas las clases, podían escuchar en la radio la obra de este compositor y otra geográfica, ya que su música enlazó distintas ciudades con condiciones y caracterizaciones etnográficas singulares.

La aristocracia barranquillera, empieza con la música popular del caribe colombiano, gracias a su alta capacidad compositiva, su magisterio con el clarinete en la improvisación, concepto orquestal a imagen y semejanza sonora de las grandes Big Band americanas principalmente tipo Duke Ellington lo va a posicionar en un mundo de respetabilidad.

Uno escucha esos solos de clarinete de Lucho y a pesar de que se combinan como si fueran los de Benny Goodman o cualquiera orquesta de swing se sabe también que se está ante un clarinete de pueblo. En una versión de la pollera colorá realizó un intercambio entre la trompeta de Miguelito Ospino y Lucho tocando su clarinete juntos; como que no sea jazz lo que están tocando es jazz ahí lo que hay es jazz pura improvisación esos solos del maestro Lucho solo los toca él, nadie más ha tocado los solos que ha tocado el maestro ni los va a tocar jamás. (Señal Colombia, febrero, 2013)

Parece un cambio osado y brusco, el hecho de que Lucho pasara de hacer jazz en la orquesta de Sosa y Radio Atlántico Jazz, a consolidar música folclórica compuesta por él mismo, pero habría que decir también, que intentó y se aventuró a componer música proveniente del interior del país, como es el caso de los pasillos, Espíritu Colombiano y Plenilunio, como resultado de estas maravillosas composiciones, el maestro Lucho con su versatilidad desafía la sociedad que miraba su música esquivamente, e implanta un nuevo estilo musical no solo en el país sino en diferentes regiones del mundo.

He aquí en pocas palabras, como la asociación de elementos musicales tomados del swing, confeccionan una perfecta combinación musical y el resultado, es una excelsa proyección cautivante, de un orden melódico y armónico que se descomponía de forma innata a la hora de improvisar.

Hay que reconocer que, en todas las obras de Lucho se cumplen diferentes funciones para la familia de las maderas y de los metales, donde en ocasiones cumplen el rol de solistas y en otras de acompañantes; a su vez, ejecutan backgrounds armónicos, backgrounds ritmo-armónicos y diferentes ambientes sonoros, fruto de la aplicación de un adecuado nivel contrapuntístico de reparto.

Se presupone, decisivamente, que con estas prácticas variables el compositor deja las costumbres ortodoxas del ayer, al orquestar las músicas indígenas de la región de la Sierra Nevada de Santa Martha y de los Montes de María, descendientes de las culturas: Kogui, Arhuaca, Ika, Wiwa, Atánque, entre otras, que forjaban sus expresiones con las gaitas, los millos, combinados con los tambores de estirpe africana y de las danzas rituales como el chicote; oportunidad manifiesta para la violación de los dogmas musicales nativos de parte de Lucho.

En la figura anterior se observa la transcripción de la improvisación realizada por Lucho Bermúdez; en el porro "fiesta de negritos", se aprecia el valor que se ilustró en la espontaneidad, invención y naturalidad en este tema: una llamada por un guía o solista (Lucho) y una respuesta como fundamento a la gran orquesta, un diálogo permanente característico de la música africana, pero que Lucho Bermúdez retoma de las músicas de gaita. Una conversación en forma de estribillo repetido a manera de ostinato rítmico-melódico, en donde se repiten las mismas frases, las cuales sirven de guía para que el solista improvise. Es necesario reiterar, que la disposición de los precitados músicos para crear, para improvisar era evidentemente fantástica, el grado de musicalidad de los artistas en escena era notoriamente excepcional. Lucho logró junto con Pacho Galán, el establecimiento y la proyección de una nueva moda, de un nuevo nivel, implantó otros imaginarios en un suceso cultural de hacer música, enmarcados dentro 


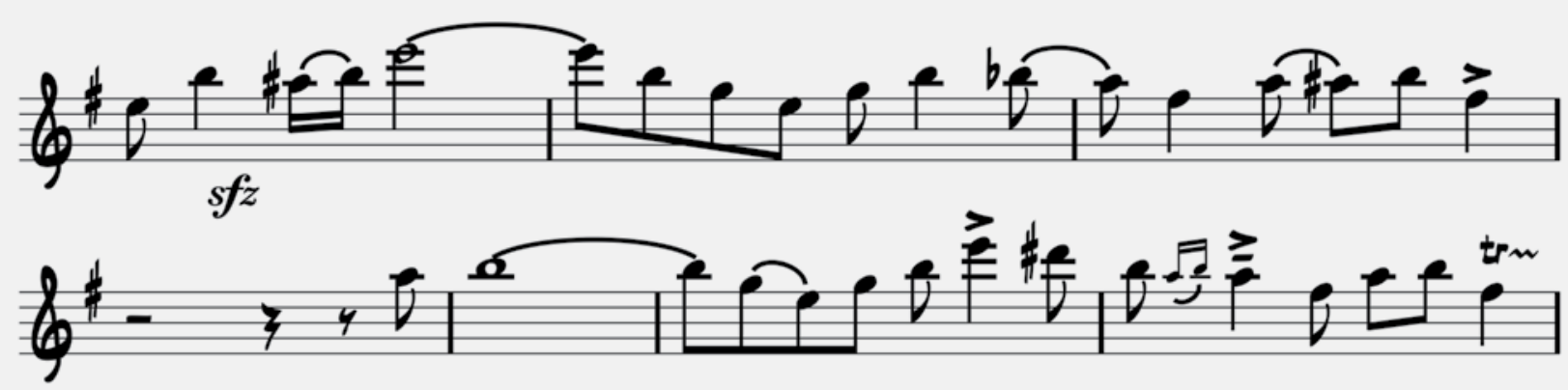

Imagen 2. Fragmento de la improvisación en Clarinete: Bb, del maestro: Lucho Bermúdez, en el porro Fiesta de Negritos. Transcripción: Realizada por los autores (Elaboración Propia).

de un panorama distinto al que la sociedad colombiana estaba acostumbrada en el entorno musical.

Además del hecho de que Lucho Bermúdez, fuera uno de los pioneros en organizar agrupaciones musicales de gran formato, se caracterizó por tener una facultad creativa inmensa, no solo para componer sino para innovar, acciones que lo llevaron a ser unos de los más prolijos en su género, y constituirse en un gran compositor y arreglista.

Cuando el Maestro Lucho Bermúdez se desempeñaba como director de su propia orquesta, desde la década del cuarenta, inquieto con la iniciativa de orquestar la música indígena, con la introducción de elementos melódicos y de orquestación que caracterizaban el jazz, los lenguajes musicales propios del swing, se convirtió por consiguiente en el colonizador del formato BigBand en Colombia; su labor se debió a la inquietud musical y a la formación académica, como es bien sabido por todos, fueron tan perfectas y complejas las improvisaciones que realizó como solista en su clarinete, al mejor estilo de Benny Goodman, que debieron ser transcritas, hacía lo que se le venía a su mente portentosa. Hasta ahora, dichos bordones son interpretados tanto en los espacios académicos, como en los entornos más populares, nunca serán sacados de la memoria colectiva; legado musical, del cual pasarán muchos pero muchos años para que el mundo pueda seguir teniendo el gusto de compartir la obra de este magnífico músico.

\section{Décadas sesenta y setenta}

Cuando las Big-Band se acrecientan a lo largo de las décadas de los años 60 y 70, de la misma forma como aparecieron Lucho Bermúdez y Pacho Galán, sobran razones para echar un vistazo al proceso que configuraron otras agrupaciones, con acciones parecidas de hacer y grabar música digno de mencionar. En nuestro país vecino, lo propio fue realizado por la BigBand de América, Los Melódicos de Venezuela y Billo's Caracas Boys, orquestas que retoman en gran parte el repertorio de los compositores referenciados con anterioridad, y adicionalmente incorporan dentro del escenario tropical, la movilización de danzones, son cubano y rock and roll.

De forma similar, en Colombia nace la Orquesta de los Hermanos Martelo, como lo indica el documento sobre las historias del Magdalena: "Fue la primera orquesta donde la mayoría de los integrantes eran hermanos y estaba formada por cuatro trompetas, tres saxofones, tres trombones, congas, timbales, batería, piano y contrabajo". Inicialmente esta orquesta no tenía cantantes, después de establecerse en Santa Marta, esta agrupación se radica en Medellín, (Ospino,2017). Habría que afirmar también la demanda característica de los hoteles, discotecas y salones de baile a finales de los años 70 sobre las orquestas de gran formato, ya que, la gran afluencia de muchedumbre demandaba que la música fuera animada en vivo por las Big-Band, lo que propició el fácil sostenimiento para conservar orquestas de planta en estos sitios referenciados. Hacia los sesenta, la big band, Orquesta La Voz de Cali (compuesta por cubanos, costeños y caleños) interpretaba jazz en sus programas radiales en la capital del Valle (Muñoz, 2007, p. 75).

Los formatos Big-Band que caracterizaban las orquestas de Lucho y Pacho Galán, fueron conservados en buena parte por el resto de las orquestas colombianas; posteriormente aparecen en Colombia orquestas como las de German Carreño en Medellín, Los Caribes, la orquesta del sincelejano, ya desaparecido, Juancho Torres. 


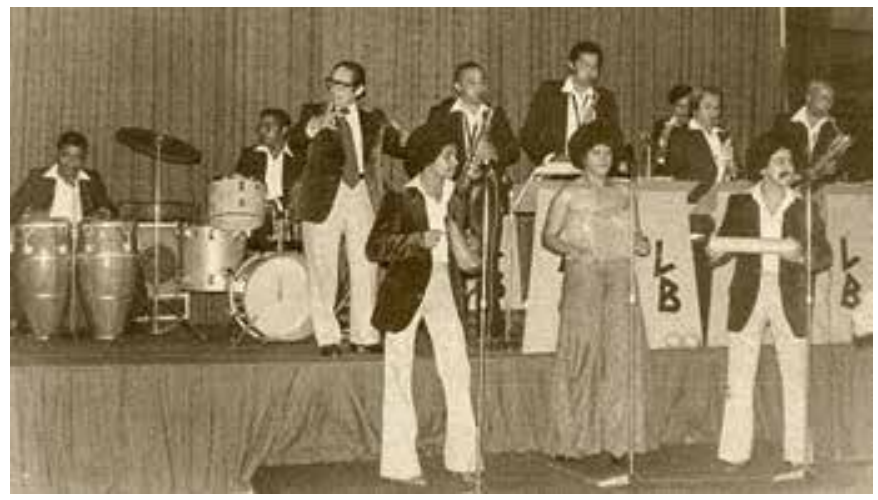

Posteriormente, en 1978 se organiza la Colombia All Stars, con el propósito originario fue la salsa, de gran trascendencia dentro de las organizaciones musicales de gran número de músicos, por la calidad de integrantes que logró reunir su virtuosismo y tecnicismo, en lo citado a continuación, expresa la conformación efímera de este proyecto ambicioso, en su intención de emular la expresión musical de la Fania All Star, del Maestro Johnny Pacheco, generando una conciencia musical local y regional.

La Colombia All-Stars, fue una orquesta inmensa concebida y amamantada en Bogotá, el único lugar que en ese momento hubiese podidos servir de centro estratégico para una orquesta que en algún momento contó con más de 20 músicos y que además tuvo una tremenda ambición. Pero por muy grande que haya sido la idea y la orquesta, esta tuvo una brevedad legendaria. (ahcma.wordpress.com, 2014)

Regionalmente, el Gran Santander no estuvo ausente de las conformaciones de las grandes orquestas. Esta disposición fue latente en el apogeo entre las décadas de los 60 a los 90. La producción musical en Cúcuta estuvo protagonizada por la gran orquesta del maestro Manuel Alvarado, La Orquesta Elegante de Colombia, que no solo realizaba montajes de música tropical, como se le llamó en ese entonces a la música popular, también incluía en su repertorio temas como "In the Mood" y "Moonligth Serenade" de Glenn Miller. Esta orquesta estaba conformada básicamente por cuatro trompetas en Si bemol, dos trombones, dos saxos altos, dos saxos tenores, un saxo barítono, piano, bajo, percusión y cuatro cantantes. Es de anotar que las cuatro trompetas realizaban voces independientes, no como otras agrupaciones que la cuarta trompeta dobla la voz de la primera trompeta octava abajo.
Imagen 3. La famosa Big-Band: de Lucho Bermúdez. Fuente: http:// luchobermu.blogspot.com/2012/02/carrera-orquestal.html

En Bucaramanga se estableció y funcionó la orquesta del maestro Alfonso Guerrero, la cual surge para deleitar sobre todo en salones de baile, toda la zona de influencia de Santander, Norte de Santander, Boyacá y la Costa Caribe colombiana, esta agrupación logró cautivar al público en el florecimiento y la fuerza de la salsa y el merengue entre otros ritmos.

\section{Las Big-Band en la modernidad colombiana}

En la actualidad, en la geografía colombiana se destacan distintas orquestas, que proyectan su música para contextos y públicos especiales, una de ellas es la La Big Band Bogotá, proyecto que nace en 2010; así mismo se encuentra en el Valle la Cali Big Band, dirigida por el maestro José Aguirre.

En Colombia hoy por hoy, existen músicos profesionales y seguidores que participan en distintas agrupaciones y son de la calidad de Antonio Arnedo y Justo Almario, que proporcionan bondades musicales a la sociedad; de manera similar, las políticas estatales y las instituciones de educación superior, promueven en el interior de sus claustros, la conformación de agrupaciones dedicadas a ensamblar diversos tipos de músicas, más por la pasión o por la atracción apremiante de hacer música, que por la necesidad de fundamentar una sociedad sostenible y estable culturalmente, todo lo anterior sumado a que comercialmente, es insostenible mantener agrupaciones de gran tamaño, y la sociedad en muchas ocasiones, observa con desdén este tipo de música elaborada de modo profesional.

Dentro del contexto universitario en Colombia, a la fecha se encuentra la Atlántico Big-Band, dirigida y fundada por el maestro Guillermo Carbó. Esta bigband se articula con la necesidad de propiciar un 
espacio académico, a los estudiantes del programa de Licenciatura en Música de la Universidad del Atlántico, estrategia utilizada hoy en día por algunas universidades para la práctica y ocurrencia de algunos ritmos estadounidenses.

En Medellín, actualmente, existe la Trópico Big-Band, perteneciente a la casa disquera Merlín Producciones, a la que también pertenecen Puerto Candelaria y la trompetista Maité Hontelé, en entrevista realizada al maestro Juancho Valencia (fundador, productor, arreglista y director artístico de la Trópico Big Band), relata lo siguiente:

La Trópico Big Band, tiene una cantidad de proyectos diarios, entonces, digamos que la desarrollamos más para proyectos específicos, estamos más enfocados a desarrollar proyectos específicos más que en tener una Big-Band desarrollándose cierto, yo he tenido la posibilidad de estar en contacto con las Big-Band de diferentes partes del mundo, y pues la Big-Band, es un elemento que es subsidiado por el Estado en gran parte del mundo. (febrero, 2017).

La gestión cultural a través de proyectos acumula un excelso y variado saber que se revela y al mismo tiempo se proyecta en el complejo entrecruzamiento de miradas musicales, en donde se mueve la sociedad actual Colombiana, que revela bien el progreso en el que persiste, la música hecha por las big band, a pesar de los múltiples factores para que estas agrupaciones musicales perduren por un prolongado tiempo, las posibilidades de subsistencia son inestables, es más fácil aplicar estrategias de unión determinantes, para jalonar la música por tiempos más prolongados.

La perspectiva musical de las big band pareciera que encuentra su sitio en el año 2006. Nace en Bogotá Carrera Quinta Big-Band, creada en ese año por Javier Pérez Sandoval y Francy Montalvo, combinando elementos e influencias de las músicas tradicionales, de la región andina colombiana y conceptos de otras músicas como el jazz. En 2009 presentaron su primera producción discográfica llamada "En esencia"; En 2016 lanzan su nueva producción "Carrera Quinta Big Band", financiada tras un exitoso proceso de "crowdfunding" llevado a cabo en el año 2015.

Carrera Quinta, es una de las mejores maneras de darnos cuenta que estamos en un momento musical donde la ciudad de Bogotá puede tomar los lenguajes sonoros tradicionales y unirlos con los actuales, sin por ello dejar de pensar en un legado musical nuevo.(Plata Manjarrés, Carrera Quinta, 2015)

En las notas publicadas por Carrera Quinta, se establece que en el año 2006 esta agrupación fue ganadora de la Beca de Investigación en Música, otorgada por el Ministerio de Cultura. En 2009, incluye su trabajo como una de las experiencias más destacadas y apoyadas en los 10 años del programa de Estímulos a la Creación. La obra en esencia, que le da nombre a su primer disco, fue ganadora en la convocatoria de composición, del Banco Virtual de Partituras y la Batuta en 2009, además de ser nominadas premio Latin Grammy en la categoría de Mejor Álbum de Jazz Latino.

En Santander, existe en la actualidad la orquesta DR Big-Band, la cual surgió en 1999 como una materia de práctica orquestal del currículo académico del pregrado en música de la Universidad Autónoma de Bucaramanga (UNAB). La iniciativa fue del maestro ucraniano Dmytro Ryeznik, docente de este programa, quien interesado en difundir el jazz, convocó a un grupo de estudiantes universitarios y conformó la agrupación con este formato actualmente en Bucaramanga.

\section{Conclusiones}

Las sociedades contemporáneas por su naturaleza compleja han mutado, y estas circunstancias han propiciado innovaciones dentro de la organización de las grandes orquestas, en función del hacer técnico y de producción musical, que gracias a su práctica han establecido nuevos imaginarios culturales, con todas estas incorporaciones melódicas, armónicas y rítmicas, evocando nuevos referentes dentro de la historia de la música.

Las reflexiones anteriormente elaboradas, conducen a establecer discernimientos, comprensiones y asociaciones sobre lo que sucedió en Colombia, con manifestaciones musicales organizadas en formatos tipo big band; su ubicación dentro de la línea de tiempo, su evolución en la historia musical de Colombia, desde 1917 hasta la actualidad, acompañado de la referencia a sus principales precursores y creadores, la transición de las orquestas de jazz a la música popular y folclórica, el funcionamiento complejo organológico y compositivo; todo el anterior análisis interpretado razonablemente dentro de un complejo social y sus distintas repercusiones, enmarcado en la identidad cultural, y en la 


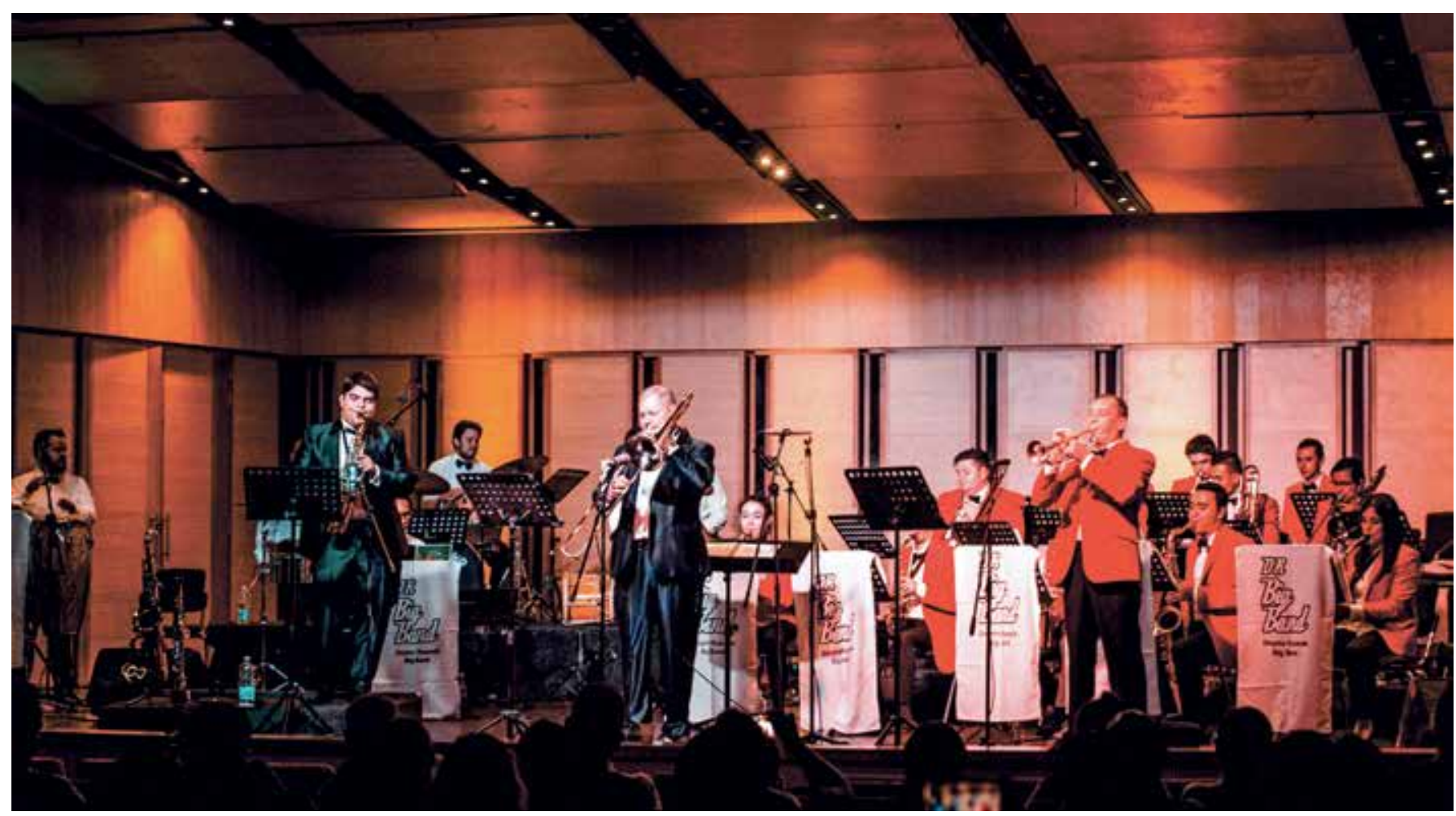

Imagen 4. Big-Band Universitaria (Archivo Fotográfico Personal).

inclusión de la música en la memoria colectiva de la historia musical del país.

La música oral y escrita como expresiones culturales, en forma de melodía y armonías que proporcionaron los músicos de las generaciones anteriores como herencia, dejaron estelas perpetuas, que cualquier persona puede reconocer auditivamente, generaron impactos relevantes y gusto por dichas músicas, que se quedarán guardados en la descendencia, en una reminiscencia colectiva permanente, y en el patrimonio inmaterial, todo ello para consolidar la identidad, no solo de la sociedad colombiana sino del mundo entero, es el caso de las obras de los citados artistas que forjaron nuevos estilos y fusiones popularizando el folclore colombiano, al hacer música a través de sus orquestas, a diferencia de la música precaria que hacen los músicos en la modernidad, con fines solo comerciales y que duran en la retentiva de las personas pocas horas o semanas, este fenómeno hace que la sociedad se deslegitime y no proceda a reconocerse en sí misma.

\section{Referencias}

ACMa. Wordpress. Disponible en https://ahcma. wordpress.com/2014/04/28/la-colombia-all-starsuna-orquesta-que-duro-96-horas/
Carrera Quinta. https://carreraquinta.com/ [Acceso: 2017, enero 28]

[Músicos de provincia integrantes de una Jazz Band]. (Norte de Santander. 1930). Archivo Museo fotográfico de Toto Villamizar.

García, C. (1990). Culturas híbridas. Estrategias para entrar y salir de la Modernidad. México DF: Edición Grijalbo. https://doi.org/10.1080/13569329209361789

Historias del departamento del Magdalena. Historia Orquesta Hermanos Martelo. Disponible en https://www.facebook.com/permalink.php?story_ fbid=1578329449090237\&id=1495630230693493

Diario La provincia. (2005). “El mejor Jazz y Swing con 'La orquesta de Glenn Miller." Disponible en http://www. lasprovincias.es/20140130/ocio/musica/glenn-millerorquesta-palau-201401301053.html.

Osorio, I. (2014). Reseña histórica de las vías en Colombia. Ingeniería Solidaria, 10(17), pp. 183-187, (enero-diciembre). DOI: http://dx.doi. org/10.16925/in. v10i17.880 
La Colombia All-Stars. [En línea], https://ahcma. wordpress.com/2014/04/28/la-colombia-all-stars-una-orquesta-que-duro-96-horas/

Mauleón, R.(1999). 101 Montunos. USA: Petaluma. ISBN 1-883217-07-5

Muñoz Vélez, L. E. (2007). Historia del jazz en Colombia: desde los alegres años 20 hasta nuestros días., Barranquilla, Colombia: La Iguana Ciega.

Oliver García, R.I. (2009). Travesía Hibridación y viajes del jazz en Colombia y su influencia en la música local. (Tesis). Bogotá: Pontificia Universidad Javeriana,.

Ospino Rangel, R. (2017). Orquesta de las Hermanos Martelo Disponible en http://historiasdelmagdalena. blogspot.com/2017/04/orquesta-hermanosmartelo.html.
Samper, A. S. (2003). De la Orquesta Sosa a la Emisora Atlántico Jazz Band. La conformación de un gusto musical. Caribania Magazín 2003. Disponible en https:// caribaniamagazine.webcindario.com/1AJULY6/h_jl/ sossa.htm

Señal Colombia. (23 de febrero de 2011). Lucho (Documental). [En línea] disponible en https://www. youtube.com/watch?v=uEWGnFjnjXs\&tt=1664s

Wade P. (2002). Música, Raza y Nación: Música Tropical en Colombia. (Trad.) Adolfo González Henríquez. Bogotá D.C., Colombia: Editorial Multiletras Editores. 